\title{
Training and Education - Mission of Essence in the Development of the Individual and Society
}

\author{
Galina Martea \\ PhD, member of the Romanian-American Academy of Sciences and Arts, The Netherlands \\ galinamartea@yahoo.co.uk
}

\begin{abstract}
The essential role of education and training is to maintain and develop the intellectual and spiritual balance of the individual in a social environment, thus forming, in time, the appropriate personality and identity. The individual, in his turn, with his knowledge, skills and intellectual and spiritual wealth, accumulated over the years in educational institutions, as well as other education and training structures, will contribute in a decent and civilized mode to the welfare and development of their own society, in this way, giving a meaning to the spiritual, intellectual, as well as material content that brings satisfaction and benefit in personal and social life. Thus, education and training, based on a set of values that are regularly applied to the formation of the intellectual and moral traits of an individual, are those actions that have as objective the evolutionary improvement of the social environment, considered to be the best substance regulated by the individual. Thus, both man and the social environment are both a whole of the existence through which mutual exchange of values and actions takes place, which in the process of development equally necessitates frequent transformations in development.
\end{abstract}

KEYWORDS: mission, training, education, individual, social environment, development

\section{Introduction}

Being a strict necessity for both man and society, education evolves uninterruptedly through a series of transformations that, on their turn, bring into action important activities that develop the social environment and the individual in the same way. Through continuous training and education, as a priority commitment of a social environment, a condition is created that forces and imposes the individual to always be in direct contact with teaching, thus, through the process of learning the man is able to attain those decent experiences and things that, can bring spiritual and intellectual wealth throughout his entire live. Correspondingly, through the evolutionary processes, the man is the development model that produces the necessary changes both in the education system and in the social system of existence. As a social identity, the individual becomes that substance in existence which through culture and education endlessly favours the pursuit of actions in promoting evolutionary processes, thus creating favourable conditions in his own development and his own society. In this way, the communication and the qualitative correlation between man and society is formed, and education presents itself as an intermediary factor between them, having the function of realizing common beneficial actions and, respectively, of fostering the social development that would be based on economic and political structure. In its turn, the economic and political development of society as a priority attracts in itself the educational factor, a social component that determines the structuring of domains on actions and principles based on the scientific theories of pedagogy, as a consequence, realizing the necessary social product. Thus, the necessary product that man and the developing society need is created, and through these transformations the condition is realised that depends on the occurrence of phenomena that produce the diversity of the environmental factors through which the human being exists.

Based on the element of education, the relationship between man and society includes that active principle of existence through which the science of pedagogy, which is a function and role in the individual and social development, is fully based. Thus, pedagogy as a science in the formation and training of the man is the activity by which the human values of social character are reproduced and the field by which the processes of behaviour and communication between the individual and the society are valorised. 


\section{The analysis on training and education as mission of essence in the development of the individual and society}

With the continuing process of teaching occurs the evolutionary action of permanent change of man in relation to the social environment. The teaching, being the system of theoretical and practical guidance in various fields, is also the system by which intellectual development is acquired and spiritual wisdom is enriched, thus creating a multilateral system of human culture. The notion of teaching merges both the processes of training, as part of the enlightenment and the formation of educated human personality for a society, and the processes of education, as part of ensuring a multilateral development of human with intellectual, moral, aesthetic and physical qualities with the beneficial purpose of contributing to the formation of a civilized society. Education, based on a set of values and measures that are applied regularly for training the intellectual and moral traits of a man, also represents those measures / actions that have as objective the evolving improvement of the social environment (considered as a commodity possessed by humans) which merges the human experiences of life and culture, influenced by all methods used for this purpose. Thus, both the man, and also his social environment are a whole of the existence through which mutual exchange of values and actions takes place, which in the process of development equally necessitates frequent transformations in development. In parallel, there is that cross between the actions that associate the proposed objectives with the desired results. By remodelling processes of human existence man, with his own society, was developing that model that produces those changes and in the education system.

Education, being a social activity, is expressing character through clear forms to convey to the rising generation those essential educational components which influence the development of human faculties systematically and consciously and, which, respectively, ensure that enlightenment of the society. Working in this mode, through education is formed also that social component that acts as an element of evolution thanks to which are influenced a whole variety of values necessary to the human development, and namely: spiritual, intellectual, material values. Through these values created by the man and via which them, in turn, formed the man, are constantly changing, in parallel through them was formed also the science of education on the basis of which also was and remains man with its intellect and culture.

Man, as a social individuality is that substance in human life that through culture and education favours forever to carry out actions as the absolute necessity of evolutionary processes, thus creating favourable conditions to designed events and phenomena of the human being and its society. Phenomena in turn is a category that is manifested in attitudes, behaviour, tendencies towards actions with material values, spiritual, intellectual, they are a direct link between human activities and social developing human society. Through this relationship, education is that function that sends the adequate communication in the correct formation of systems and subsystems from society necessary for the man and, respectively, sends the adequate communication in the formation of cohabitation qualitative correlation between society and the individual. Through communication and qualitative correlation between man and society, education is presented as an intermediary between these function factor to achieve beneficial joint action and to promote social development, based on economic and political structure. Namely, economic and political development of a society draws itself as a priority factor determining educational domains structuring actions based on scientific theories of pedagogy, as a result, producing product with the required effect. Indispensable, the product is created that is needed by the man in the development and prosperity of the society.

Those transformations are also manifested and in the diversity of conditions that depend on the occurrence of phenomena that are produced in all the environmental factors through which the human being exists. These, like others, are a direct connection with education, and can make causes by negatively influencing, and as positively the transformation of social life, provoking in the same time, adverse effects on human consciousness that supports the changing variety of its existence. The occurrence of such phenomena can carry out stimulating actions or of apathetic nature (inactive) that can cause misunderstandings in fulfilment of personal and social obligations. As a 
result, those effects related to the quality of social education (eg, lower level) restrict the human behaviour through actions thus distorting the social product of development.

The relationship between man and society, founded by the element of education, includes that active principle of existence on which is based the science of pedagogy as role and function in development. Pedagogy, science of education and training of human, is the activity that reproduces the human values with a social character and is the domain in which are valued the processes of behaviour and communication between the individual and society. Through the definition or the above phrase, is reflected the image of education, as a concept, achieved through the science of teaching and, directly, done by professors/teachers with special training. Education, being a strict necessity for the man, as well for society, evolves through a series of transformations permanently putting into action the exercise of those activities developing the social environment and the individual. As priority of society, education, educational and instructive process, is the human condition that requires man to be always in direct contact with teaching.

Only by learning, the man is able to reach those experiences and things that bring them spiritual and intellectual richness lifelong. In this regard, John Amos Comenius (Czech theologian, philosopher, educator) in a general reflection on improving human relations, notes that "With regards to all humanity worldwide life is a school, from the beginning till the end of time, life for every human being is a school, from cradle to grave"(Comenius. 1633). Thus, the key role of training and education is to maintain human and spiritual balance in a social environment, thus forming its personality and identity. The man, in his turn, with the knowledge, skills and intellectual and spiritual wealth accumulated over the years, is to contribute to the welfare of their society, in a way, giving meaning to the spiritual and material content that brings satisfaction in personal and social life. Consequently, through the direct and permanent contact of learning, the man can easier integrate into society, while using its personality through processes that contribute to human and social development. Education, as a system, activates based on pedagogical science and vice versa and, respectively, pedagogical science activating through the education system, forms that function which, consequently, is rediscovering herself evolutionarily through contents and methodologies of continuous remodelling of the human being. By position to contribute positively to human formation, education, as a value, must fulfil the mission to form the man with the ability to meet the needs imposed by society. As a result, the social life of man backed by actions and deeds form a whole that is the level of civilization, progress and development of a society. The level of development is reflected in the spiritual and material existence of the society, and man, with his the culture, is the core through which the educational process takes effect.

The effect of education, as a process, updates its existence by its liabilities covering all elements of a whole of social-human principles with the role of composing proper and continuous communication between man and society, based on the substance with which creates a genuine link of actual development. On this theme on the formation of man through the correlation between education and nature, the great Greek philosopher Democritus states: "Nature and education are similar; for education transforms the man and, through this transformation, creates nature"(Democritus). But the great Chinese philosopher Confucius said: "Nature resembles us, education distinguishes us"(Confucius).

To contribute substantially to form a society and an authentic personality, then the education will contribute in the most creative and effective way through all the factors and elements of the education system. When establishing an authentic educational system, it is necessary to communicate with the educational policy, with its concept that correctly reflects the reality, with the environmental factors in which the individual reflects his action through the way of thinking and consciousness, with the state policy intersected by the art and science of pedagogy, with the actual presence of managerial and didactic staff in the life of the child-all in their turn being the core of social development through which the science of pedagogy is transmitted, and the man-childstudent and his parents are part of the existence of all the processes realized through the unit of education, which is teaching, culture, intellect, evolution. By appropriate correlation, education may find its place in a social environment, manifesting itself as a value via all forms of existence. By 
educative and instructive forms, the educational system performs its action both within the school and outside it, keeping constantly in touch with organic internal and external factors of the social environment. Under the influence of internal and external factors are also included formal and nonformal forms on the basis of which lays the variety of institutions with school and extracurricular activities, extra didactic.

Consequently, all are available to the individual in order to learn and gain as much knowledge and skills in various fields. Formal education conducted within the school (from pre-school to the academic system) in relation to non-formal education achieved outside the classroom (and outside school), differs among them by the teaching content, methods and their characteristic forms. Finally, formal education is that form of education and training that creates complete human personality in relation to the personality of society, and the non-formal education enables the man to enrich/complete more and more his culture and intellect made through formal education, thus using its full identity of man in society. The educational unit, being the foundation of all forms of education and training, is also the value through which the human goes through to rediscover itself as a value-learning and particular individuality of a social environment. These values, in turn, forms the principle of existence which requires man to respect and appreciate the importance of social content and the importance of common development strategy.

Following the ideas of Comenius we can confirm with certainty that education embraces the whole life of the human being, giving him wisdom and reason throughout its existence. By its functions, education expresses real presence in the development of human and social life and human faculty forms depending on the capabilities of the society. Capacity or human faculty expressed through moral and intellectual qualities is also, and its function that is performed in an organized manner to achieve a particular purpose. Human purpose, if it can be defined this way, is nothing more than the objective towards which the man is aiming to namely achieve a civilized existence in a civilized social environment. This correlation filtered through his own and social being requires the man to create the conditions for the existence of beneficial growing influence, stimulating as much the development of their own society. The development of a society, which is based on the educational system and continuing education, expresses its true face only if is able to meet the requirements and satisfy the needs of the individual, that represents the totality of phenomena of economic, cultural and social nature. Through all these phenomena is identified the man with his skills and knowledge, conditioned by the educational processes. The human being through education establishes the conditions that determine the occurrence or development of a phenomenon. The phenomenon, being a materialist dialectics category correlated to the essence, forms the essential processes in relation to their dependent nature of human existence. Processes, in turn, are manifested through action developed, having function and role in the established topic. Identically, the education manifests itself as a phenomenon and action, with the function and role in the development of the human being and the society.

So, through continuous training and education, as a priority commitment of a social environment, a condition is created that imposes the individual to always be in direct contact with teaching. Correspondingly, through the evolutionary processes, the man is the development model that produces the necessary changes both in the education system and in the social system of existence. As a social identity, the individual becomes that substance in existence which through culture and education endlessly favours the pursuit of actions in promoting evolutionary processes, thus creating favourable conditions in his own development and his own society. In this way, the communication and the qualitative correlation between man and society is formed, and education presents itself as an intermediary factor between them, having the function of realizing common beneficial actions and, respectively, of fostering the social development. As an argument, based on the educational element, the relationship between man and society forms the active principle of existence, and the pedagogy, as a science in the formation and training of the man, represent the activity by which the human values with social character are reproduced and, respectively, the action is developing by which the processes of behaviour between the individual and the society are valorised. 


\section{Conclusions}

Therefore, the essential role of education and training is to maintain and develop the intellectual and spiritual balance of the individual in a social environment, thus forming, in time, the appropriate personality and identity. The individual, in his turn, with his knowledge, skills and intellectual and spiritual wealth, accumulated over the years in educational institutions, as well as other education and training structures, will contribute in a decent and civilized mode to the welfare and development of their own society, in this way, giving a meaning to the spiritual, intellectual, as well as material content that brings satisfaction and benefit in personal and social life. Thus, education and training, based on a set of values that are regularly applied to the formation of the intellectual and moral traits of an individual, are those actions that have as objective the evolutionary improvement of the social environment, considered to be the best substance regulated by the individual. Thus, both man and the social environment are both a whole of the existence through which mutual exchange of values and actions takes place, which in the process of development equally necessitates frequent transformations in development. Thus, education is a social activity that expresses its character through clear forms in order to convey to the growing generation those essential educational components that systematically and consciously influence the development of human faculties and, which, respectively, ensure the culture of the respective society. By activating in that way, education also forms the social component that acts as an element of evolution, influencing the whole range of values necessary for the developing person, namely: spiritual, intellectual, material values.

\section{References}

Comenius, John Amos. 1633. "From a process of general reflection on the improvement of human relations." http://lcmkroon.wordpress.com/2014/05/30/ how-to-be-in-a-relationship-or-not/.

Confucius. Quote. Point 11. https://1 cartepesaptamana.ro/40-de-citate-despre-educatie/.

Democritus. Quote. Point 28. http://www.humanistictexts.org/democritus.htm. 